\title{
Mulvihill-Smith syndrome: case report and review
}

\author{
Oliver Bartsch, Klaus-Dieter Tympner, Eberhard Schwinger, Robert J Gorlin
}

\section{Institut für}

Klinische Genetik,

Universitätsklinikum

Carl Gustav Carus der

Technischen

Universität,

Fetscherstrasse 74,

01307 Dresden,

Germany

O Bartsch

\section{Städtische}

Kinderklinik, 81545

München-Harlaching,

Germany

K-D Tympner

\section{Institut für}

Humangenetik,

Medizinische

Universität, 23562

Lübeck, Germany

E Schwinger

School of Dentistry, University of

Minnesota,

Minneapolis

MN 55455, USA

R J Gorlin

Correspondence to Dr Bartsch.

Received 8 March 1994 Accepted for publication 21 April 1994
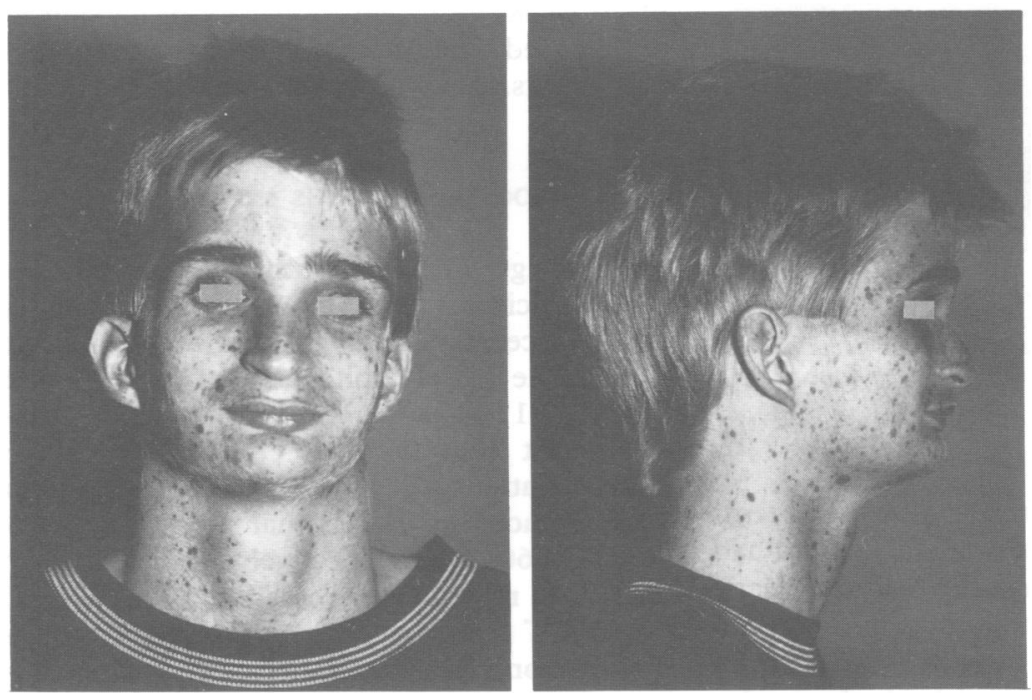

Figure 1 Facial views of the patient aged 17 years, showing a prematurely aged, small, bird-like face, small, low, protruding ears with hypoplastic lobes, scant subcutaneous fat, microcephaly, numerous pigmented naevi, reduced lower facial height, micrognathia, and absent beard.

(f Med Genet 1994;31:707-711)

The Mulvihill-Smith syndrome (McKusick 176690 ) is a rare sporadic condition. In 1975, Mulvihill and Smith reported a mildly mentally retarded 17 year old male with very short stature, microcephaly, numerous pigmented naevi and freckles, hypodontia, chronic infections, and insulin dependent diabetes mellitus, and diagnosed the same condition in a previously reported 4 year old mentally immature boy. ${ }^{1-3}$ In 1988, Baraitser et $a l^{4}$ recognised another

\begin{abstract}
We report a 20 year old man with short stature, microcephaly, unusual facies, numerous pigmented naevi, hypodontia, immunodeficiency, and a high pitched voice. Tympner et al had assumed that the patient had a new syndrome of "progressive combined immunodeficiency and ectomesodermal dysplasia". We show here that the condition is identical to the Mulvihill-Smith syndrome (McKusick 176690), a progeroid disorder described in four or possibly five sporadic cases to date. We describe his clinical progress up to the age of 20 years. Our patient suffered from severe viral infections, allergic rhinitis and conjunctivitis, delayed puberty, visual loss, modest achievement in high school, and reactive depression. The immunological, facioskeletal, and dental abnormalities are presented in detail.
\end{abstract}




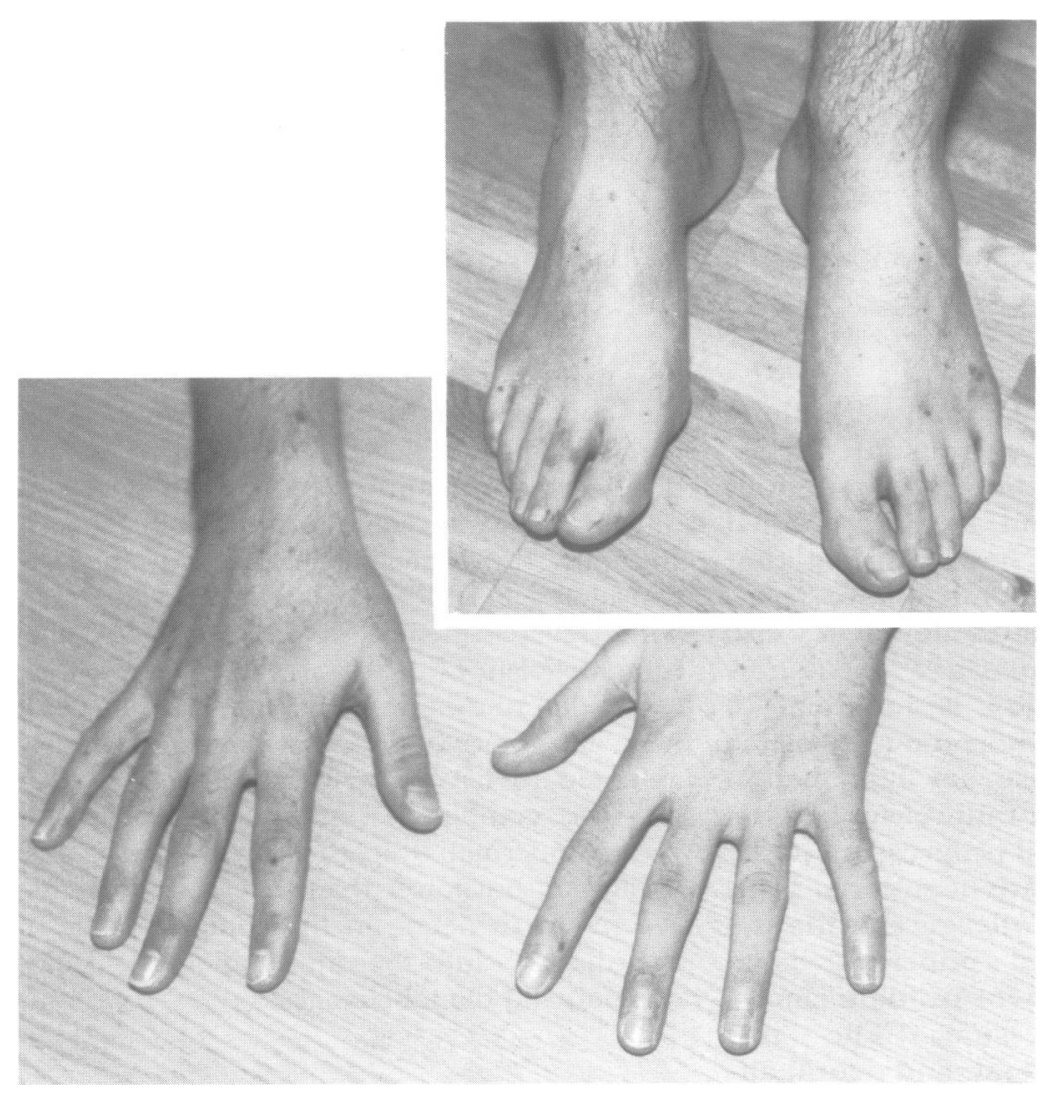

Figure 2 Hands and feet at the age of 17 years, showing long, slender fingers and toes, clinodactyly $V$, numerous naevus cell naevi, and mild hirsutism.

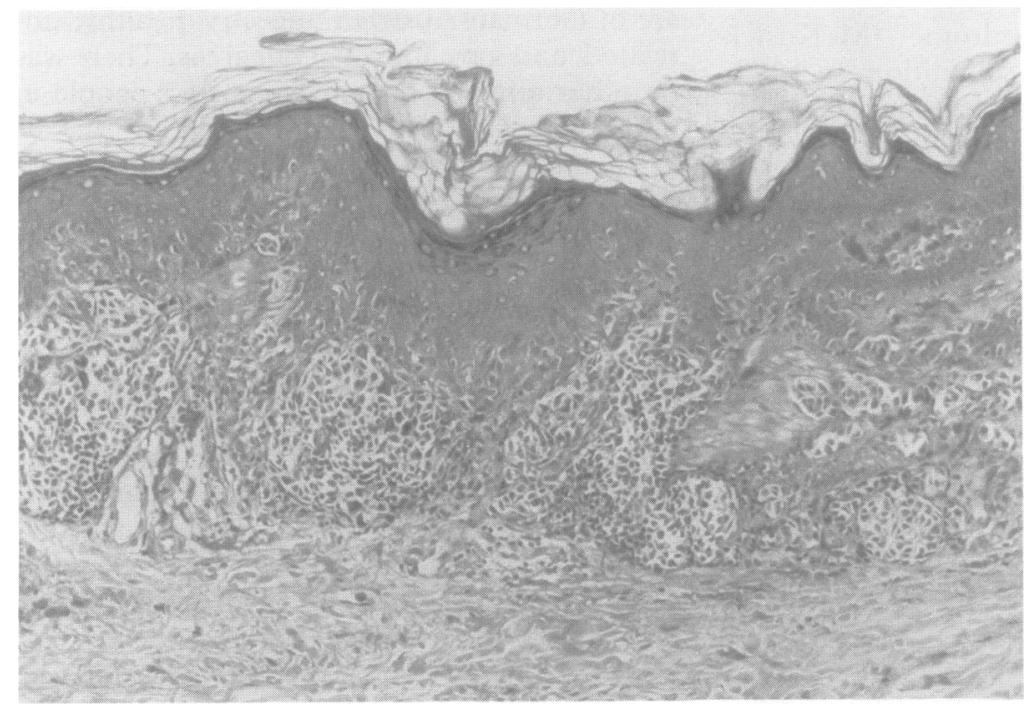

Figure 3 Skin histology at the age of 15 years, showing nested naevus cells within the basal stratum of the epidermis and within the corium. Diagnosis: melanocytic naevus (syn naevus cell naevus), compound type. The compound type melanocytic naevi have a significantly lower risk of malignant degeneration than the epidermal type melanocytic naevi, which are located more superficially.

and elementary school from 7 years. His temperament was pleasant, he was active, and had good verbal skills. Around the age of 8 years, the pigmented naevi increased in number.

$\mathrm{He}$ had good school reports and was admitted to the Gymnasium (the highest educational level in the German school system) at the age of 13 years.

From 13 years 3 months he was treated with growth hormone $(\mathrm{GH})$ because of short stature $(139 \mathrm{~cm},-2.6 \mathrm{SD})$ and subnormal results in a GH stimulation test.

Visual acuity declined and was corrected by contact lenses. Findings included myopia, astigmatism, keratoconus, dystrophy of the corneal endothelium, and chronic conjunctivitis. At 15 years 5 months, he had severe varicela with a fever above $40^{\circ} \mathrm{C}$ for a week. He recovered with antiviral medication (acyclovir) School achievment decreased despite his best efforts. Contacts with his peers became fewer, indicating depression. At 16 years, LEOPARD syndrome was diagnosed. There was a spontaneous fracture of a protuberance from the left hip bone (the apophysis spina iliacae anterior inferior sinistra) during school sports, requiring three weeks of immobilisation.

We saw the patient at the age of 17 years (figs 1,2 ). He closely resembled the patient of Mulvihill and Smith ${ }^{1}$ and suffered from school problems, short stature, delayed puberty, visual loss, severe allergic rhinitis, frequent infections, and depression. Height was $160.2 \mathrm{~cm}$ ( $-2.6 \mathrm{SD}$ ), weight $44 \mathrm{~kg}$ ( $-11 \%$ with regard to height), and OFC $51 \cdot 8 \mathrm{~cm}(-3 \cdot 1 \mathrm{SD})$. Vision was corrected by contact lenses. The skin was dry. He had severe chronic conjunctivitis and stomatitis, small brittle teeth with enamel defects, and absent second bicuspids. Numerous naevi measuring 2 to $10 \mathrm{~mm}$ in diameter (fig 3) were located mainly on the face and shoulders, with some even on the palms and soles.

There was mild hirsutism and clinodactyly $\mathrm{V}$ of the hands and feet. Puberty was delayed. The voice had not changed, testis size was reduced (left $5 \mathrm{ml}$, right $6 \mathrm{ml}$ ), pubic hair was stage $\mathrm{Ph}$ IV, and penis was stage G II-III (Tanner). Bone age was estimated at 17 years 6 months using a hand radiograph (Greulich and Pyle), and GH treatment was finished. Relative height had remained constant with $\mathrm{GH}$ administration, resulting in a final height of $160 \cdot 2 \mathrm{~cm}(-2.6 \mathrm{SD})$.

At 19 years he failed in class and left school, having completed 10 school years with success. $\mathrm{He}$ took supportive psychotherapy. At the age of 20 years, he began to learn a profession in a sheltered institution. He received corneal transplants. The voice was still high pitched.

\section{IMMUNOLOGICAL FINDINGS AND LABORATORY} STUDIES

At the age of 15 months, combined immunodeficiency with constant lymphopenia and reduced IgA and IgG was diagnosed. At 4 years he had lymphopenia of 384-1677/ $\mu$ l (normal 1500-4000) and low-normal leucocytes at $3200-9600 / \mu \mathrm{l}$. Of the lymphocyte subpopulations, $B$ cells and mature $T$ cells were reduced at $0 \%$ (nomal 4-14) and 54\% (normal 60-80), respectively; $\mathrm{T}$ suppressor cells were relatively increased at $30 \%$ (normal 11-29). T cell function by $\left[{ }^{3} \mathrm{H}\right]$ thymidine incorporation after stimulation and mitogen exposure was greatly reduced at $787 \mathrm{cpm}$ with phytohaemagglutinin (controls 32 000-50 000), at $6823 \mathrm{cpm}$ with concanavalin $\mathrm{A}$ (controls $40000-49000)$, and at $2623 \mathrm{cpm}$ with 
pokeweed mitogen (controls 15000-26000). Lymphotoxin activity after phytohaemagglutinin stimulation was also reduced. IgA and IgG were decreased at $0-0.95 \mathrm{~g} / 1$ (normal $0 \cdot 32-1 \cdot 8$ ) and $2 \cdot 88-6 \cdot 1 \mathrm{~g} / 1$ (normal $5 \cdot 2-13 \cdot 7$ ), respectively; $\operatorname{IgM}$ was normal at $0.34-1.05 \mathrm{~g} / 1$ (normal $0 \cdot 4-2 \cdot 06$ ) and IgE was increased at 444-523 U/ml (normal <15). Granulocytes were normal in number and function. Quantitative and qualitative $B$ and $T$ cell deficiency was diagnosed.

At 17 years, serum IgA and IgG were normal. $\mathrm{IgM}$ and $\mathrm{IgE}$ were increased at $5.0 \mathrm{~g} / 1$ (normal $0 \cdot 49-3 \cdot 20$ ) and $1420 \mathrm{U} / \mathrm{ml}$ (normal $<28$ ), respectively. CD3 + T cells and CD $4+T$ helper

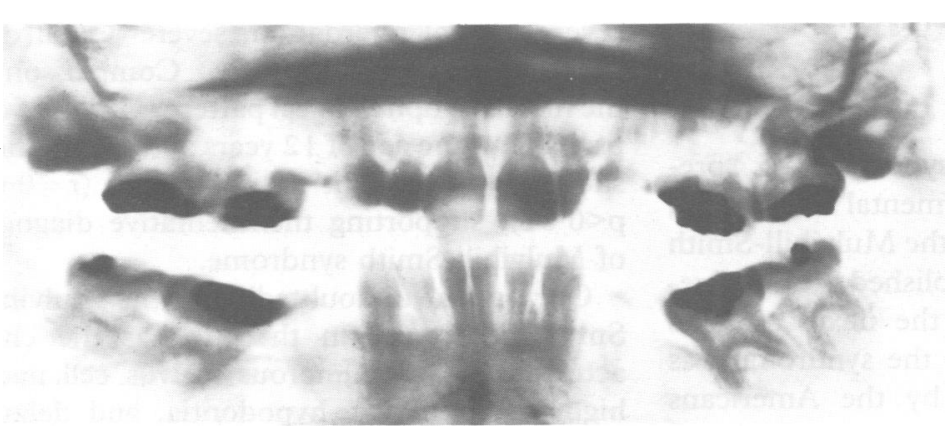

Figure 4 Orthopantogram at the age of 11 years 7 months. The upper second incisors 12 and 22 have cone chaped crowns. There are no bicuspids 15, 25, 35, and 45

(hypodontia). The lower first molars 36 and 46 are tilted forwards. The molars have shortened roots (taurodontism). The anlagen of the upper third molars 18 and 28 are tilted anteriorly, and there are no anlagen of the lower third molars 38 and 48.

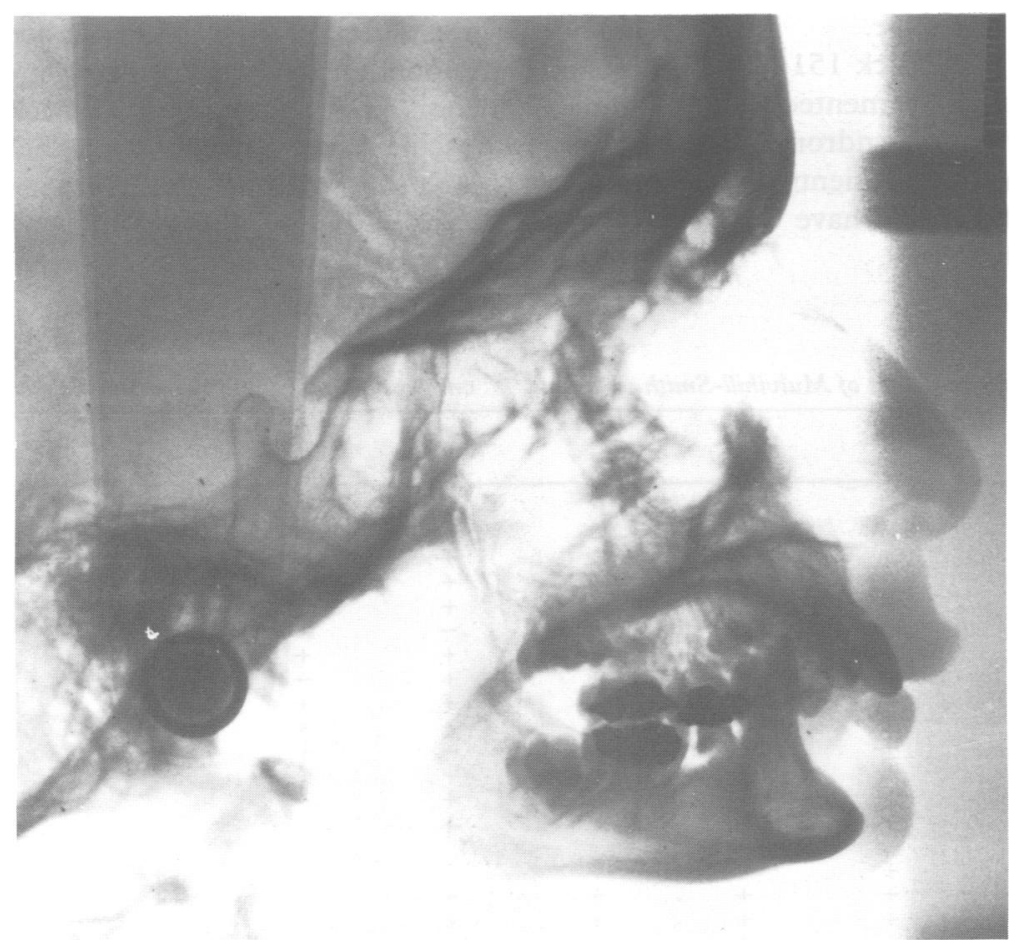

Figure 5 Lateral skull radiograph at 12 years, showing marked hypoplasia of the vertical facial skeleton, especially affecting the alveolar processus of the mandible and maxilla, slight horizontal reduction of the maxillary basis as compared to the basinasal length, and significant horizontal reduction of the body and ramus of the mandible. This results in micrognathia, an overbite, forward tilted lower incisors, and compression of the soft parts of the lips and chin. cells were reduced. Serum cholesterol was moderately increased at $6.19,6.73$, and $6.86 \mathrm{mmol} / \mathrm{l}$ (normal $<5 \cdot 18$ ). Triglycerides and lipid electrophoresis indicated type IV hyperlipidaemia on one occasion and were normal on another occasion. Normal routine laboratory tests included RBC, WBC, and leucocyte differentials. FSH was increased, $\mathrm{LH}$ was normal, and serum testosterone was decreased. Standard chromosome analysis in 1977 had been normal.

\section{RADIOGRAPHS}

An orthopantogram at the age of 11 years 7 months (fig 4) showed cone shaped upper second incisors 12 and 22. The bicuspids 15, 25, 35,45 and the lower third molars 38 and 48 were absent (hypodontia). The lower first molars 36, 46 and the anlagen of the upper third molars 18 and 28 were tilted forwards. The molars had enlarged coronal pulp and reduced roots (hypotaurodontism).

The lateral skull radiograph at the age of 12 years (fig 5) showed marked hypoplasia of the vertical facial skeleton, mainly affecting the alveolar processes of the mandible and maxilla. Horizontally, the maxillary basis was slightly reduced as compared to the basinasal length, while the body and ramus of the mandible were significantly reduced $(-2 \mathrm{SD})$. This resulted in micrognathia, supraocclusion (overbite), compensatory forward tilt of the lower incisors, and compression of the soft parts of the lips and chin.

$\mathrm{AP}$ and lateral skull radiographs at the age of 16 years showed dolichocephaly, thick calvaria, facial skeletal hypoplasia, nasal septum deviation, hypoplastic dental lamina, micrognathia, and swollen mucous membranes of the maxillary sinuses. Radiocephalometry (Bergen method) indicated a biparietal diameter of $15 \mathrm{~cm}$, skull length of $21.5 \mathrm{~cm}$, height from base to vertex of $17.5 \mathrm{~cm}$, maxillary depth $9 \mathrm{~cm}$, mandibular depth of $10.5 \mathrm{~cm}$, and facial skull height $12.5 \mathrm{~cm}$. The cephalic index of 70 indicated dolichocephaly (normal 75-84); the three dimensional brain skull index of 54 indicated normal brain volume, and the three dimensional facial skull index of 32 indicated reduced facial skeleton. A cranial CT scan at the age of 16 years showed no cerebral abnormalities.

Metacarpophalangeal pattern profile analysis at the age of 5 years (fig 6 , upper curve) showed an unusual growth pattern with normal mean bone length $(0.09 \mathrm{SD}) .{ }^{9}$ At the age of 12 years ((fig 6, lower curve) the pattern was remarkably similar (correlation between patterns: $r=0.71$, $\mathrm{p}<0.001$ ), but marked growth failure had resulted in shortness of the metacarpals and phalanges (mean bone length $-1.8 \mathrm{SD}$ ). The growth failure was more clearly seen in the distal phalanges, most markedly affecting the distal phalanx of the thumb ( $-3.54 \mathrm{SD})$.

\section{Discussion}

This man was described in 1978 in a German paediatric journal as having a new syndrome. ${ }^{8}$ 


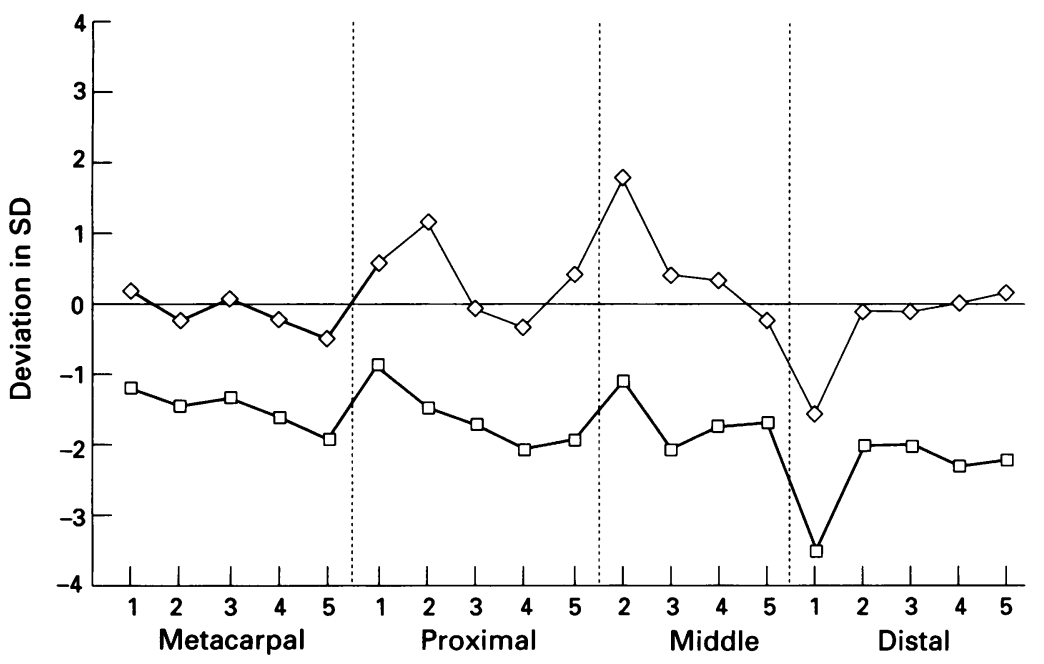

Figure 6 Metacarpophalangeal pattern profiles of the patient at 5 years (upper curve) and 12 years (lower curve), showing significant similarities between the patterns (correlation $r=0.71, p<0.001$ ) and marked growth failure between the ages of 5 and 12 years.
Three years earlier, the syndrome of "premature aging, growth and mental retardation, and peculiar facies", today the Mulvihill-Smith syndrome, had been established, ${ }^{1}$ but it received no attention until the next case was recognised in $1988 .{ }^{4}$ Thus the syndrome was delineated independently by the Americans Mulvihill and Smith and the Germans Tympner, Belohradsky, Eife, and Klose.

The Mulvihill-Smith syndrome is a rare condition; only five or possibly six patients including our proband have been described to date. We confirm here that it represents a separate entity among at least 30 progeroid syndromes. The clinical features of the syndrome are summarised in the table.

LEOPARD syndrome (McKusick 151100), another disease with numerous pigmented skin lesions, resembles the present syndrome in short stature and hypogonadism. Patients with LEOPARD syndrome, however, have lentigines and not naevus cell naevi.
The Mulvihill-Smith syndrome is a clinically complex disease, in that numerous different tissues of the body are affected. A single gene mutation is possibly the cause of the diverse symptoms. The striking resemblance between the different cases of Mulvihill-Smith syndrome supports the idea of a mutation at a single locus as the cause of the disease. Autosomal recessive inheritance has been suggested by parental consanguinity in the case of Ohashi et al. ${ }^{7}$ We cannot add support to this suggestion, but it is of possible interest that our patient and the patient of Mulvihill and Smith are of GermanAustrian descent. ${ }^{1}$

Ohashi et $a l^{7}$ considered Mulvihill-Smith syndrome in its advanced stage as the most likely diagnosis in their patient, but did not establish a definite diagnosis because the syndrome had not been associated previously with severe mental retardation, severe $\mathrm{T}$ cell dysfunction, and brachydactyly. ${ }^{7}$ Comparison of the metacarpophalangeal pattern profiles of our proband at the age of 12 years and their patient showed significant similarity $(r=0.63$, $\mathrm{p}<0.01$ ), supporting their tentative diagnosis of Mulvihill-Smith syndrome.

Our patient undoubtedly has the MulvihillSmith syndrome, in that he has the characteristic facies, numerous naevus cell naevi, high pitched voice, hypodontia, and delayed puberty. In addition, he has immunodeficiency, as seen by subnormal $\mathrm{B}$ and $\mathrm{T}$ cell counts, changes in immunoglobulin levels, functional $\mathrm{T}$ cell defects, severe allergic rhinitis, and frequent viral infections. This supports the notion that severe combined immunodeficiency can be a characteristic of the syndrome.

The pathogenesis of the naevus cell naevi is unknown. Pigmented naevi occur in a number of genetic immunodeficiency syndromes, including Fanconi pancytopenia (McKusick 227650), Maraschio-Peretti type chromosomal instability (McKusick 251260), and $\mathrm{N}$ syndrome (McKusick 319465). Naevus cell naevi of the junctional type were described after ther-

Clinical and laboratory findings in four cases of Mulvihill-Smith syndrome, ${ }^{1-46}$ one possible case, ${ }^{7}$ and the proband

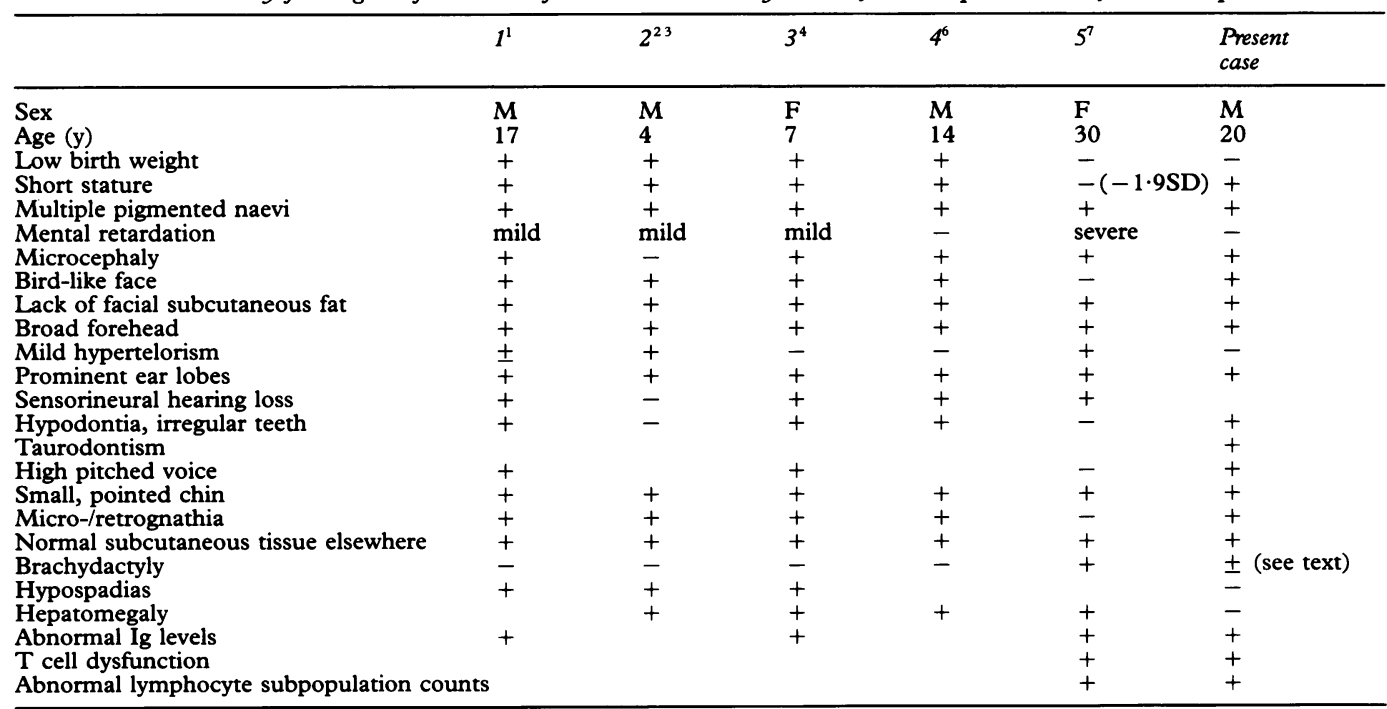


apy for leukaemia in a monozygotic twin, where the possibility of mutagenic effects of cytostatic therapy on somatic cells in a state of induced immunoincompetence was considered. ${ }^{10}$ Thus, immunodeficiency and naevi are possibly related in Mulvihill-Smith syndrome.

It is well known that lipid metabolism disorders can occur in the progeroid syndromes, for example, in Hutchinson-Gilford progeria. Hypercholesterolaemia was observed in another case of Mulvihil-Smith syndrome ${ }^{6}$ and in our patient. More observations are needed to clarify whether hypercholesterolaemia represents a typical manifestation of the syndrome.

Taurodontism (taurus: steer) has not been described in Mulvihill-Smith syndrome to date; however, incomplete dental root development and reduced alveolar height was reported in the case of Wong et al. ${ }^{6}$ Mesotaurodontism, that is, the more marked form of taurodontism, has been described in fossil humans (Homo Heidelbergensis), while the milder form of hypotaurodontism can occur in modern human populations (American Indians, South African Bantu-Boskop-hybrids). Taurodontism results from delayed development of the HertwigBruhn'sche epithelial division between the dental roots. The trait may be of diagnostic value in future cases. Interestingly, taurodontism has been associated with autosomal dominant inheritance and Klinefelter's syndrome.

Our patient and his mother were disturbed to learn that Mulvihill-Smith syndrome has been associated with mental retardation. They were afraid of early onset progressive mental deterioration because of his increasing failure in school. This point deserves further attention. Follow up studies of the previously described patients at older ages can help to obtain more information on the long term outcome of the condition.

We thank the proband and his mother for consenting to publication, and Drs P Beyer, C Brack, P K Klose, and S StengelRutkowski for clinical information on the patient and Drs $R$ Fischer and $G$ Kanitz for invaluable advice on the skin histology and the skull radiographs. We are grateful to Dr D Hosenfeld for a copy of the anthropometric programme for the metacarpophalangeal profile analysis (ANTRO, version 4.72E). ${ }^{9}$

1 Mulvihill JJ, Smith DW. Another disorder with prenatal shortness of stature and prenatal aging. Birth Defects 1975; XI (2):368-71.

2 Shepard MK. An unidentified syndrome with abnormality of the skin and hair. Birth Defects 1971;VII(8):353-4.

3 Elliott DE. Undiagnosed syndrome of psychomotor retardation, low birthweight, dwarfism, skeletal, dental, tardation, low birthweight, dwarfism, skeletal, dental,
dermal and genital anomalies. Birth Defects 1975;XI(2): dermal

4 Baraitser M, Insley J, Winter RM. A recognisable short stature syndrome with premature aging and pigmented naevi. F Med Genet 1988;25:53-6.

5 Gorlin RJ, Cohen MM, Levin LS. Syndromes of the head and neck. 3rd ed. New York: McGraw-Hill, 1990:487-8. 6 Wong W, Cohen MM, Miller M, Pruzansky S, Rosenthal IM, Solomon LM. Case report for syndrome identification. Cleft Palate f 1979;16:286-90.

7 Ohashi H, Tsukahara M, Murano I, et al. Premature aging and immunodeficiency: Mulvihill-Smith syndrome? $A m \mathcal{F}$ Med Genet 1993;45:597-600.

8 Tympner KD, Belohradksy B, Eife R, Klose PK. Progressiver kombinierter Immunodefekt mit ekto-mesodermaler Dysplasie. Klin Padiatrie 1978;190:610-13.

9 Hosenfeld D, Hosenfeld F, Schaefer E, Grote W. IBM-PC compatible software for establishing metacarpophalangeal pattern profiles. Clin Genet 1991;39:396-400.

10 Heyne K, Hof M, Hansen HG. Pigmented naevi after therapy of leukaemia (ALL) in a monozygotic twin. Eur f Pediatr 1984;142:70. 